\title{
ROLE OF SPRING CATCHMENTS OF REDUCING PESTICIDE TREATMENTS IN BACTROCERA OLEAE MANAGEMENT PROGRAMS
}

\author{
Ali, Essam A. \\ Department of Plant Protection, Desert Research Center, Cairo, Egypt \\ E-mail: essamnewaaa@yahoo.com
}

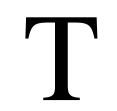

he olive fruit fly Bactrocera oleae is the most important olive pest. This study was conducted in El Matarih, Marsa Matrouh in Matrouh Governorate, Egypt during 2013 and 2014, to illustrate the relationship between adult captures occurred in McPhail traps and in soil cages inactivity period (from January to May) and their effects on the infestation levels on olive fruits in active period (from June to November). In McPhail traps, data showed two main peaks inactivity periods, the first peak was in March and the second was in May. Data demonstrated that adults by the $1^{\text {st }}$ of January was in a relatively low number (about 7.5 adults) and increased gradually to reach its main peak on March, where the average number reached about 117.2 adults and the second peak with value of 116.2 adults in May. McPhail traps caught female adults more than male and captured (74.7 and 73.5) and (42.5 and 42.7) in female and male adults in March and May months, respectively. In soil cages, the average number of adults were decreased sharply throughout the successive inspection and reached the lowest numbers (1.4 adults/10 cages) in January. The average number of emerged adults were increased gradually in the successive inspection and reached the second highest average numbers (22.5 adults/10 cages) in March. Also, adult females were found to be more dominant than males and recorded the highest average numbers in December, 2013 (30.6 adult females/cage) and recorded the lowest average numbers in January, 2013 (0.9 adult females). Based on our data in the activity period, the cumulative average number of total infested fruits, larvae and pupa as affected by dimethoate spraying and mass trapping in inactivity period were (14.0, 3.2 and 3.6) and (22.8, 5.8 and 5.9), respectively, as compared with $(83.9,20.7$ and 21.2) fruits in the untreated control treatment, representing $(83.3,84.5$ and $83.0 \%)$ and $(72.8,72.0$ and $72.2 \%)$ reduction of infestations, respectively. These observations support some of recommendations to control olive fruit fly by removing pupa in the soil, destroying fruit left on the tree after harvest and mass trapping of olive fruit fly inactivity period. In addition to this 
natural control, there are no pollutants in olive fruit and its oil contents. The obtained data support that it is possible to carry out previous recommendations in inactivity period in order to prevent or reduce adulticide treatments to improve IPM or organic management in areas where high infestation is expected.

Keywords: olive fruit fly, mass trapping, overwintering population, inactive period, soil cages

Olive fruit fly (Bactrocera oleae (Gmelin), Diptera: Tephritidae) is the most serious insect pest of olive fruits in the world. This pest causes huge economic damages, caused by infestation of fruits by larvae and fruit drop. It affects the olive tree cultivation causing serious qualitative and quantitative consequences with economic impacts and monetary losses (Neuenschwander and Michelakis, 1978 and Economopoulos et al., 1986). Indirect damage can be measured through decrease of olive oil quality, caused by larvae activity inside the fruit that suffers by nutritional changes of mesocarp degradation and oxidation process and finally, increase of oleic free acids. Even with the pesticide treatments that are applied every year to control the olive fruit fly population, the damage caused by this insect in the fruits, results in about 10-30\% loss of the olive crop (Economopoulos et al., 1982 and Economopoulos, 2002). This suggests resistance in insect populations and needs for study alternative or complementary management techniques. Without treatment and under optimum climate conditions, for the development of the olive fruit fly, the insect could infect up to $100 \%$ of the olive fruits (Athar, 2005). The adults, although active all year round if temperatures are suitable, are only of economic concern during the growth period of the olive fruit. Egg laying and damage normally commence in early summer although most of the damage occurs in the autumn, when the fruit is maturing. Control of olive fruit fly depends on either killing the hatching eggs and larvae in the olive fruit or stopping the female from mating or laying eggs.

Adults may migrate on large scale from the interior hill zones to the coastal plain ones to find favorable climatic conditions or available host fruits. Adults move on a small scale from the olive groves to feed on other host plant females, after mating enter reproductive diapauses till the olive fruits are suitable (Raspi et al., 1997 and 2002). The olive fruit fly overwinters as a pupa in the soil although a proportion of the population can emerge during the winter months. Most adults emerge in spring. Currently researches focus their studies on $B$. oleae management during the infestation season, while the ecology and biology of overwintering populations are not very well-known under field condition in Egypt. The relationship between $B$. oleae spring adults population in the soil and early summer adults population has not been shown until now.

Egyptian J. Desert Res., 65, No. 1, 137-151 (2015) 
Some authors observed flights of male and female adults during the spring season from March to May (Neuenschwander et al., 1986) and were observed peaks of captured adults during April at landscape scale. Ragaglini and Petacchi (2004) and Melis (1953) observed that all the pupae survived, from those collected in autumn, developed in adults before May. Other authors (Raspi et al., 1996) reports that during April about $60 \%$ of caught females had mature eggs. In some previous studies at regional scale, that identified areas where high infestation levels occurred since early summer and in one of these areas landscape scale investigation was carried out by the use of a pheromone traps or McPhail traps network. Large peaks of captured adults were observed during spring then the captures decreased during May and raised up in late June (Ragaglini and Petacchi, 2004). The captures of olive fruit fly during April were caused by adults developed from overwintering pupae in the soil and these adults complete another generation before July. The aim of this work was to control olive fruit fly by studying the relationship between spring adults captures occurred in the inactivity period (from January to May) and its effects on the infestation levels on olive fruits in active season (from June to November). Also, the best time of hanging traps on trees in the next winter and autumn seasons was studied to prevent or reduce the infestation of olive fruit fly and reduce adulticide treatments to improve IPM or organic management in areas where high infestation is expected.

\section{MATERIALS AND METHODS}

\section{Location and Illustration of the Studied Olive Orchard}

The experiment was conducted in olive grove located in El Matarih, Marsa Matrouh in Matrouh Governorate, Egypt, that has a typical Mediterranean climate. The orchard was planted with 20 -year old cv Manzanillo olive. All trees were similar and subjected to the same agriculture practices. The experiment was conducted during 2013 and 2014. During the experimental months, the weather was characterized by moderate to high temperature $\left(23-31^{\circ} \mathrm{C}\right.$ average daily), moderate humidity, slight to moderate winds and lack of rainfall, so the orchard is watered from an artesian well. On the whole experimental area olive harvesting usually finishes before December, so until May no host fruits are available.

\section{Sampling Techniques}

The evaluation of the method of treatment that compared in these tests was based on adult pest population density records in traps from December to May (inactive period) and on fruit infestation levels from July to November months (active period) during the experimental period. Three treatments with four replicates were arranged in a completely randomized block design. Olive fruits were examined for the three presences of the 
number of infested fruits, pupal and larval tunnels. Each replicate consisted of five trees. Samples of 25 fruits from each tree (replicate) representing different levels and directions of the trees were randomly collected to investigate olive fruit fly attacking fruits. Total infestation levels were calculated. Fruit damage was assessed every 15 days comparing with the control up to the harvest of the crop. Samples were collected in paper bags and examined in laboratory for insect infestation by using stereoscope microscope. The percentage of reduction in infestation was calculated according to the formula of Topps and Wain (1957) and Ali (2006).

$\mathrm{R} \%=\left(\frac{\mathrm{C}-\mathrm{T}}{\mathrm{C}}\right) \times 100$

Where:

C: number of insects recorded in the check samples.

$\mathrm{T}$ : number of insects recorded in treatment samples.

\section{Treatment Methods}

\subsection{Inactivity period}

\subsubsection{Mass trapping technique to capture adults of olive fruit fly}

Overwintering populations (inactive period) was studied at landscape scale monitoring olive fruit fly Bactrocera oleae using McPhail plastic traps (Potamitis et al., 2014) from winter till early summer. A network of twenty traps was used to sample adults from 2013 to 2014. A bait solution was di-ammonuim phosphate $(3 \%)$ and water. Traps also require the most maintenance, because of their tendency to dry out in hot weather. Therefore, they were hung in the shade and water level was frequently checked (FAO, 2015). The solution had to be changed once a month. In all the following experiments, the traps were hung on the trees at a height of 1.5 to $2 \mathrm{~m}$ and inside of the south side of the tree in the shade. Four replicates were arranged in a completely randomized block design. The olive orchards were regularly irrigated. Traps were checked each ten days from December to May in a regular schedule. At each check the position of the traps within each tree was re-randomized. Liquid lures were renewed every two weeks with water, while synthetic dispensers were replaced every month. At each check, the number and sex of olive fruit flies captured were recorded.

\subsubsection{Relation of soil under olive trees to resultant populations by using pupa cage technique}

In this experiment, cage techniques have been used to determine the time emergence of adults of olive fruit fly from the pupa in spring and winter seasons (inactive period) to know the reasonable time for hanging olive fruit fly trap in overwintering season (Yokoyama et al., 2006).

Some soil samples were collected from under 10 trees that contain some pupa. Soil with pupa was placed in a small cage and was left to give a 
chance to pupa to emerge adult stage. Ten cages were put under ten trees in the middle of November. Cages were examined each 15 days at the beginning of December to the middle of June in a regular schedule. At each check the number and sex of olive fruit flies were recorded.

\subsection{Activity period}

The olive trees were sprayed (five times) every 21 days with dimethoate formulation from the first of July to November (till harvesting) against olive fruit fly. Spraying was repeated again in August, September, October and November with the same insecticide. Spraying was accomplished by a six horses power motor sprayer "Beem" with $600 \mathrm{~L}$ tank, at the rate of $12-16 \mathrm{~L}$ per tree. Check trees were left without treatment $(20$ trees). For all treatments, samples of 100 infested fruits/treatment were collected immediately before spraying as index of pre-treatment count, and every 15 days after the six successive sprays to determine the infestation level.

\section{Data Analysis}

The data were subjected to analysis of variance according to completely randomized design.

\section{RESULTS AND DISCUSION}

\section{Inactivity period}

\subsection{Eficiency of mass trapping to capture adults of olive fruit fly}

Data obtained from three counts monthly of $B$. oleae are given in tables (1 and 2). These results revealed that total numbers (male and female) of $B$. oleae olive fruit fly were found captured in McPhail traps throughout inactivity period, which extended from December, 2012 to May, 2013. Data demonstrated that two main peaks of olive fruit fly adults occurred during the inactivity seasons in March and May, with few minor peaks differed in number, which showed the activity pattern in each season (Mansour et al., 2015). During January, 2013, the total numbers were few (10.9 adults). Then, insect population increased gradually. Afterwards, total numbers of adults were recorded the highest adults captured in traps in March, 2013, being 91.6 adults. Then, decreased and reached in May, 2013, being 68.9 adults. Results showed efficiency of McPhail traps in capture females than males during inactivity periods of olive fruit fly, B. oleae, where the highest number of males and females captured were recorded (51.55 adult females and 40 adult males) in March, 2013. The lowest numbers of both males and females were recorded in January, 2013 (7.1 adult females and 3.9 adult males). 
Table (1). Average number of adults of Bactrocera oleae captured in McPhail traps, during inactivity period, on olive trees in North Coast, Matrouh Governorate in 2013 season.

\begin{tabular}{cccc}
\hline Sampling dates & Famale & Male & Total \\
\hline Dec. 2012 & 36.4 & 21.5 & 57.9 \\
Jan. 2013 & 7.1 & 3.9 & 10.9 \\
Feb. 2013 & 22.0 & 14.0 & 35.9 \\
Mar. 2013 & 51.6 & 40.0 & 91.6 \\
Apr. 2013 & 29.5 & 21.5 & 50.9 \\
May 2013 & 42.0 & 26.9 & 68.9 \\
\hline
\end{tabular}

Data in the second season had the same trend as the first season. In the second season, 2014, table (2) showed two main peaks that occurred during the inactivity period, the first peak was in March and the second was in May. It is evidence from the data that the occurrence of adults in the $1^{\text {st }}$ of January was in relatively low number (about 7.5 adults) and increased gradually to reach its main peak in March, where the number reached an average of 117.2 adults. The insects started to decrease gradually from the inspected dates in April and reached to the second peak in May with value of 116.2 adults. McPhail traps caught female adults more than male and captured (74.7 and 73.5) and (42.5 and 42.7) in female and male adults in March and May, respectively. These data agreed with Ragaglini et al. (2007), who said that olive fruit fly, Bactrocera. oleae had inactivity period during December to May and activity period during June to November. Ragaglini and Petacchi (2004) confirmed that the high infestation levels occurred since early summer investigation by the use of a pheromone traps or McPhail traps network. Large peaks of captured adults were observed during the spring, then the captures decreased during May and rise up in late June. These results agree with the findings obtained by Yokoyama et al. (2006), who found that the highest numbers of pupae were collected from non-harvested fruit in March, when high numbers of adults were captured in the same orchard. The above mentioned results revealed that potential effect of the olive fruit fly population appeared during the activity season depended mainly on the number of adults occurred during inactivity season, where the male and female adults occurred during that period emerged during these overwintering months. Therefore, it is supposed that, the high density of $B$. oleae population in early summer are due to better climatic conditions for overwintering pupae in the soil and for spraying emerged adults, thus the risk of infestation since July is very high, when the traps catches adults of olive fruit fly in overwintering month with high potentially, then the investigation of fruits in activity period with olive fruit fly should be decreased during the mature fruit months on olive trees. So, catchment of the adults of olive fruit fly may prevent using insecticides in heavy spraying. Ragaglini et al. (2007) agrees with that it is possible to carry out spring Egyptian J. Desert Res., 65, No. 1, 137-151 (2015) 
preventive adulticide treatments to improve IPM or organic management in areas where high infestation is expected.

Table (2). Average number of adults of Bactrocera oleae captured in McPhail traps, during inactivity period, on olive trees in North Coast, Matrouh Governorate in 2014 season.

\begin{tabular}{cccc}
\hline $\begin{array}{c}\text { Sampling } \\
\text { dates }\end{array}$ & Female & Male & Total \\
\hline Dec. 2013 & 34.7 & 20.8 & 55.4 \\
Jan. 2014 & 5.0 & 2.5 & 7.5 \\
Feb. 2014 & 26.4 & 16.1 & 42.4 \\
Mar. 2014 & 74.7 & 42.5 & 117.2 \\
Apr. 2014 & 36.7 & 13.8 & 50.4 \\
May 2014 & 73.5 & 42.7 & 116.2 \\
\hline
\end{tabular}

The results of trapping populations of olive fruit fly adults in Matrouh has shown that in general, McPhail traps are effective in capturing adults and attract a greater proportion of females than males. More adults are captured in traps in the spring and fall months, when fruit is available and conditions are cool and humid, than in winter and summer. Fruit that remains in the tree or in the soil after the previous year's harvest is a source of continuing infestations. Early season females lay and larvae develop into adults in very small immature fruit. These observations support the use of control practices such as sanitation and timed sprays that will help reduce crop damage (Yokoyama et al., 2006).

\subsection{Relation of soil under olive trees to resultant populations}

Data obtained three times monthly from adult stages of $B$. oleae, which emerge from pupae are given in tables ( 3 and 4) throughout inactivity periods of olive fruit fly in 2013 and 2014.

In the first season (2013), these results showed that total adult stages were emerged from soil cages recording the highest number in December, 2012 (44.5 adults/10 cages). Number of adults were decreased sharply throughout the successive inspection and reached the lowest numbers (1.4 adults/10 cages) in January, 2013. Afterwards, the number of adults emerged were increased gradually in the successive inspection and reached the second highest number (22.5 adults/10 cages) in March, 2013. Also, adult females were found to be more dominant than males and recorded the highest number in December, 2013 (30.6 adult females/cage) and recorded the lowest number in January, 2013 (0.9 adult females/cage). The results obtained in the second season (Table 4) showed a similar trend to the first season. A greater average of females than males emerged on all evaluation dates. A highly significantly greater number of females and a significantly 
greater number of adults and males emerged from soil cages in 2014. The highest number of adults emerged in 10 cages per month occurred in December 2013, March, April and May 2014. The average of adults' emergence were $23.5,31.1,15.3$ and 17.6 , respectively, every month. The mean number of olive fruit fly pupae collected from soil (Table 4) in the previous year ranged from 17.6 to 31.1 from March through May. Pupa that remained in the soil under the trees from December of the previous year supported the immature stages of olive fruit fly into the spring (March, April and May). The number of adults per 10 cages reported in tables ( 3 and 4) can be used to calculate the potential number of adults in a spring population.

Table (3). Average number of adults of Bactrocera oleae emerged from soil cages, during inactivity period, on olive trees in North Coast, Matrouh Governorate in 2013 season.

\begin{tabular}{cccc}
\hline $\begin{array}{c}\text { Sampling } \\
\text { dates }\end{array}$ & Female & Male & Total \\
\hline Dec. 2012 & 30.6 & 13.9 & 44.5 \\
Jan. 2013 & 0.9 & 0.5 & 1.4 \\
Feb. 2013 & 7.1 & 2.5 & 9.6 \\
Mar. 2013 & 14.6 & 7.9 & 22.5 \\
Apr. 2013 & 6.6 & 3.4 & 10.0 \\
May 2013 & 8.1 & 5.5 & 13.6 \\
June 2013 & 10.7 & 6.9 & 17.6 \\
\hline
\end{tabular}

Table (4). Average number of adults of Bactrocera oleae were emerged from soil cages during inactivity period on olive trees in North Coast, Matrouh Governorate in 2014 season.

\begin{tabular}{cccc}
\hline $\begin{array}{c}\text { Sampling } \\
\text { dates }\end{array}$ & Female & Male & Total \\
\hline Dec. 2013 & 14.7 & 8.8 & 23.5 \\
Jan. 2014 & 3.4 & 1.6 & 5.0 \\
Feb. 2014 & 2.1 & 1.2 & 3.3 \\
Mar. 2014 & 19.9 & 11.2 & 31.1 \\
Apr. 2014 & 9.9 & 5.4 & 15.3 \\
May 2014 & 11.4 & 6.2 & 17.6 \\
June 2014 & 11.4 & 7.0 & 18.4 \\
\hline
\end{tabular}

Egyptian J. Desert Res., 65, No. 1, 137-151 (2015) 
This resident population would be the source of later olive fruit fly generations that would infest the current year's olive crop. Olive fruit fly, $B$. oleae had inactivity period from December to May. The data show that the hypogenous pupae wintering in the soil survive during winter and spring until June (Mansour et al., 2015). The life cycle of the olive fruit fly is synchronized with seasonal growth and olive fruit production (Zalom et al., 2009). Annual populations begin in the spring during March, April, and May, with the presence of many adults that originate from overwintering pupae and from insects developing in fruit that remain in the tree from the previous year (Yokoyama, 2015). The presence of the pupae in the soil was detected at the end of November, while persisting until the end of May to early June. Soil analysis show that the hypogenous pupae wintering in the soil survive until June. Knowledge of the factors involved in the bio-ecology of the olive fly and the phenology of the host allows the elaboration of monitoring/warning calendars, and phytosanitary measures in order to establish an IPM program adapted to the requirements of olive orchards in the region (Mansour et al., 2015). Currently collecting pupa under the trees and putting them in cages can give us the exactly time to start mass trapping in inactive period to suppress olive fruit fly populations before infestation seasons. The exact time to hang traps of olive fruit fly on olive trees after the harvest of the crop is November-December until early June. After that, the traps should be removed from the trees in insolated area, but in isolated area traps can be continued on the olive trees. The highest number of adults emerged from soil in 10 cages from the previous year occurred in overwintering before bloom (Tables 3 and 4). The presence of the immature stages, combined with high numbers of females before bloom and the susceptibility small fruit to oviposition suggests great potential for early infestations in orchards. By May, the previous year's fruit began to drop from the trees with the onset of the current seasonal bloom and was markedly decreased in quality, producing very few pupae (Yokoyama et al., 2006).

It is worthy to indicate that the data obtained are in harmony with the recommendation by Van Steenwyk et al. (2002) that removing and destroying fruit left on the tree after harvest is important in reducing olive fruit fly populations. Removing pupae from the soil under the tree were more important to control olive fruit fly. Yokoyama and Miller (2007) suggested that the availability of water may affect the number of adults found in the orchard. In our study the total number of olive fruit fly adults captured throughout the season was lower in trees without fruit and water than other test conditions. Such observations suggest that irrigation methods that minimize the availability of water and good orchard sanitation such as removing non-harvested fruit and water saturated soil will help reduce 
overwintering populations in the orchard and the resultant emergence of adults in the spring are good cultural practices to help control the pest.

\section{Activity period}

As shown in table (5), the results obtained in first season (2013) indicated that variations between the treatments in reduction and infestation percentage of B. oleae and were significantly lower in the treated olives than untreated ones. It should be mentioned that mass trapping inactive period consider economically acceptable for its strong results and for the low coast of the traps and not pollutant on the environment than insecticides applications. The cumulative number of total infested fruits, larvae and pupa as affected by Dimethoate spraying and mass trapping in overwintering season were (14.0, 3.2 and 3.6) and (22.8, 5.8 and 5.9) respectively as compared with 83.9, 20.7 and 21.2) fruits in the untreated control treatment, representing $(83.3,84.5$ and $83.0 \%)$ and $(72.8,72.0$ and $72.2 \%)$ reduction of infestations, respectively. Complete agreement was found between the above results in the first season and those obtained from the second season 2014 (Table 6) which revealed that Dimethoate application was more effective than mass trapping technique. They reduced fruit infestation by $(85.5,85.4$ and $84.6 \%$ ) and (62.2, 70.4 and 64.4\%), respectively. By using McPhail traps to catch adults of olive fruit fly in overwintering season reveled that reducing the infestation percentage from 55 to $77 \%$ without using any insecticides in summer season. The data presented here agree with those reviewed by Ragaglini et al. (2007), who found that it is possible to carry out spring preventive adulticide treatments to improve IPM or organic management in areas where high infestation is expected. On the base of our results we can hypothesize to carry out spring reducing or preventive adulticide treatments in order to decrease the population density before the infestation starts.

Table (5). Cumulative infestation by olive fruit fly (Bactrocera oleae) in olive groves, treated with mass trapping technique, in inactive period through overwintering season and dimethoate application, throughout 2013 season.

\begin{tabular}{ccccccccccc}
\hline & \multicolumn{10}{c}{ Infested Fruits * } \\
\cline { 2 - 11 } Treatments & $\begin{array}{c}\text { Total } \\
\text { number }\end{array}$ & \multicolumn{1}{c}{ Larvae } & \multicolumn{2}{c}{$\begin{array}{c}\text { Empty } \\
\text { larvae }\end{array}$} & Pupa & \multicolumn{2}{c}{$\begin{array}{c}\text { Empty } \\
\text { pupa }\end{array}$} \\
\cline { 2 - 12 } & Mean & R\% & Mean & R\% & Mean & R\% & Mean & R\% & Mean & R\% \\
\hline Mass trapping & 22.8 & 72.8 & 5.8 & 72.0 & 6.7 & 70.2 & 5.9 & 72.2 & 4.4 & 77.6 \\
Dimethoate & 14.0 & 83.3 & 3.2 & 84.5 & 4.1 & 81.8 & 3.6 & 83.0 & 3.4 & 82.7 \\
Control & 83.9 & & 20.7 & & 22.5 & & 21.2 & & 19.6 & \\
LSD & 1.1 & & 0.8 & & 0.8 & & 0.4 & & 0.2 & \\
\hline
\end{tabular}

$\mathrm{R} \%=$ Reduction percentage

*Cumulative number of infested fruits all over the growing season (12 dating samples)

Egyptian J. Desert Res., 65, No. 1, 137-151 (2015) 
Table (6). Cumulative infestation by olive fruit fly (Bactroceraoleae) in olive groves, treated with mass trapping technique, in inactive period through overwintering season and dimethoate application, throughout 2014 season.

\begin{tabular}{|c|c|c|c|c|c|c|c|c|c|c|}
\hline \multirow{3}{*}{ Treatments } & \multicolumn{10}{|c|}{ Infested Fruits * } \\
\hline & \multicolumn{2}{|c|}{$\begin{array}{c}\text { Total } \\
\text { number }\end{array}$} & \multicolumn{2}{|c|}{ Larvae } & \multicolumn{2}{|c|}{$\begin{array}{l}\text { Empty } \\
\text { larvae }\end{array}$} & \multicolumn{2}{|c|}{ Pupa } & \multicolumn{2}{|c|}{$\begin{array}{c}\text { Empty } \\
\text { pupa }\end{array}$} \\
\hline & Mean & $\mathrm{R} \%$ & Mean & $\mathbf{R} \%$ & Mean & $\mathrm{R} \%$ & Mean & $\mathrm{R} \%$ & Mean & $\mathrm{R} \%$ \\
\hline $\begin{array}{c}\text { Mass } \\
\text { Trapping }\end{array}$ & 35.8 & 62.2 & 6.3 & 70.4 & 10.3 & 58.8 & 8.8 & 64.4 & 10.5 & 55.7 \\
\hline Dimethoate & 13.4 & 85.5 & 3.1 & 85.4 & 2.9 & 88.4 & 3.8 & 84.6 & 3.7 & 84.4 \\
\hline Control & 94.6 & & 21.3 & & 25.0 & & 24.7 & & 23.7 & \\
\hline LSD & 1.6 & & 0.3 & & 0.3 & & 0.8 & & 0.7 & \\
\hline
\end{tabular}

Mass trapping can be an alternative to insecticides to control agricultural pests, including the olive fruit fly, B. oleae. This method doesn't pollute or leave residues in the fruit and insect don't develop resistance, but it can have an effect on non-target insects (Seris et al., 2009). Otherwise, pesticide can pollute the environment and obtained resistant towards the insecticides. Traps applications were used also as a tactic for IPM of olive fruits fly in olive fields (Ali, 2006). In this experiment, to make mass trapping more useful, trapping system was used to catch olive fruit fly in inactive period from last December to May (winter and spring seasons). There is no olive fruits in this period to make investigation by olive fruit fly, so there is no harmful effects on olive fruits. During spring and winter seasons, traps can catch male and female of olive fruit fly, so these catches will reduce the populations of olive fruit fly in positive trend in active season (summer season from June up to the harvest crop).

\section{CONCLUSION}

In conclusion, the obtained data support the effectiveness of masstrapping by using devices that decrease the level of active infestation by about $50 \%$, compared to untreated groves. In fact, active infestation was restrained within $62-72 \%$ until harvesting time, a percentage that is still compatible with the production of high quality oil (Iannotta et al., 2007). In order to establish recommendations for the use of mass trapping techniques in inactive period in integrated pest management strategies further studies should be done. 


\section{REFERENCES}

Ali, E.A. (2006). Integrated pest management and control of olive pests. Ph.D. Thesis, Agricultural Sciences (Pesticides), Department of Economic Entomology and Pesticides, Faculty of Agriculture, Cairo University, Giza, Egypt, p. 1-139.

Athar, M. (2005). Infestation of olive fruit fly, Bactrocera oleae, in California and taxonomy of its host trees. Agriculturae Conspectus Scientificus (ACS), 70 (4).

Economopoulos, A.P. (2002). The olive fruit fly, Bactrocera (Dacus) oleae (Gmelin) (Diptera: Tephritidae): its importance and control; previous SIT research and pilot testing. Report to International Atomic Energy Agency (IAEA), Vienna, Austria.

Economopoulos, A.P., G.E. Haniotakis and S. Michelakis (1982). Population studies on the olive fruit fly, Dacus oleae (Gmel.) (Dipt.,: Tephritidae) in Western Crete. Journal of Applied Entomology, 93: 463-476.

Economopoulos, A.P., A. Raptis, A. Stavropoulou-Delivoria and A. Papadopoulos (1986). Control of Dacus oleae by yellow sticky traps combined with ammonium acetate slow-release dispensers. Entomologia Experimentalis et Applicata, 41: 11-16.

FAO (2015). Establishment of pest free areas for fruit flies (Tephritidae). Food and Agriculture Organization of the United Nations. ISPN 26, IPPC.

Iannotta, N., M. Pellegrino, E. Perri, L. Perri and F. De Rose (2007). Mass trapping experiments with two different "Attract and Kill" devices for Bactrocera oleae (Gmelin). Integrated Protection of Olive Crops IOBC/WPRS Bull., 30 (9): 135-138.

Mansour, A.A., K. Kahime, M. Chemseddine and A. Boumezzough (2015). Study of the population dynamics of the olive fly, Bactrocera oleae Rossi. (Diptera, Tephritidae) in the Region of Essaouira. Open Journal of Ecology, 5: 174-186.

Melis, A. (1953). Nuove osservazioni sui costumi della mosca delle olive (Dacus oleae Gmel.) nella Toscana litoranea, con particolare riferimento agli sfarfallamenti invernali e primaverili. Redia, 38: 184. (C.F. Ragalini et al., 2007).

Neuenschwander, P. and S. Michelakis (1978). Infestation of Dacus oleae (Gmel.) (Diptera Tephritidae) at harvest time and its influence on yield and quality of olive oil in Crete. Zeitschrift für angewandte Entomologie, 86: 420-433.

Neuenschwander, P., S. Michelakis and E. Kapatos (1986). In "Tephritidae: Dacus oleae Gmel.”. Entomologie oleicole. Arambourg, Y. (ed.). Conseil International Madrid, p. 115-159.

Egyptian J. Desert Res., 65, No. 1, 137-151 (2015) 
Potamitis, I., I. Rigakis and K. Fysarakis (2014). The Electronic McPhail Trap. Sensors, 14: 22285-22299.

Ragaglini, G. and R. Petacchi (2004). Analisi spaziale e GIS negli studi ecologici della mosca delle olive Bactrocera oleae (Rossi) su mesoscala territoriale. - Atti III Giornate di Studio sui metodi numerici, statistici e informatici nelle difesa delle colture agrarie e delle foreste: ricerca e applicazioni. Firenze, 24-26 Novembre, p. 96100. (C.F. Ragalini et al., 2007).

Ragaglini, G., D. Tomassone and R. Petacchi (2007). Can spring-preventive adulticide treatments be assumed to improve Bactrocera oleae (Rossi) management. Integrated Protection of Olive Crops IOBC/WPRS Bull., 30 (9): 309-314.

Raspi, A., R. Canovai and R. Antonelli (1996). Andamento dell'infestazione di Bactrocera oleae (Gmelin) in oliveti del parco regionale della Maremma. Frustula Entomol., 19 (32). (C.F. Ragalini et al., 2007).

Raspi, A., A. Canale and A. Felicioli (1997). Relationship between the photoperiod and the presence of mature eggs in Bactrocera oleae (Gmel.) (Diptera Tephritidae). Proceedings of II International Open Meeting Working Group "Fruit Fly of Economic Importance". Lisbon, 22-24 September, p. 46-54.

Raspi, A., E. Iacono and A. Canale (2002). Variable photoperiod and presence of mature eggs in olive fruit fly, Bactrocera oleae (Rossi) (Diptera Thephritidae). Redia, 85: 111-119.

Seris, E., A. Cobo, S. Pascual, G.I. Cobos, P. Ros, E. Castillo, I. Sánchez Ramos, A. Marcotegui and M. González Núñez (2009). Capture of natural enemies by different devices used in mass trapping of Bactrocera oleae (Rossi). $4^{\text {th }}$ European Meeting of the IOBC/WPRS working Group Integrated Protection of Olive Crops, 70 pp.

Topps, J. H. and R. L. Wain (1957). Investigation on Fungicides III the fungi toxicity of 3 and 5-alkyl-salicyl-anilides and P-chloroanilines. Ann. Appl. Biol., 45 (3): 506 - 511. (C.F. El-Shazlyal Zein, 1983).

Yokoyama, V.Y. (2015). Olive fruit fly (Diptera: Tephritidae) in California table olives, USA: invasion, distribution, and management implications. Journal of Integrated Pest Managemen, 6 (1): 14.

Yokoyama, V.Y. and G.T. Miller (2007). Olive fruit fly biology and cultural control practices in California. Integrated Protection of Olive Crops IOBC'/WPRS Bull., 30 (9): 263-269.

Yokoyama, V.Y., G.T. Miller, J. Stewart-Leslie, R.E. Rice and P.A. Phillips (2006). Olive fruit fly (Diptera: Tephritidae) populations in relation to region, trap type, season, and availability of fruit. J. Econ. Entomol., 99 (6): 2072-2079.

Van Steenwyk, R.A., L. Ferguson and F.G. Zalom (2002). In "UC IPM Pest Management Guidelines: Olive Insects and Mites". University of California, Agriculture and Natural Resources Publication, 3452.

Egyptian J. Desert Res., 65, No. 1, 137-151 (2015) 
Zalom, F.G., R.A. Van Steenwyk, H.J. Burrack and M.W. Johnson (2009). In "Olive Fruit Fly: Pest Notes". University of California Agriculture and Natural Resources Publication 74112, Oakland. (http://www.ipm.ucdavis.edu/PDF/PESTNOTES/pnolivefruitfly.pdf)

Egyptian J. Desert Res., 65, No. 1, 137-151 (2015) 


\title{
دور الإصطياد الربيعي لتقليل إستخدام المبيدات في برامج مكافحة ذبابة ثمار الزيتون المبنات
}

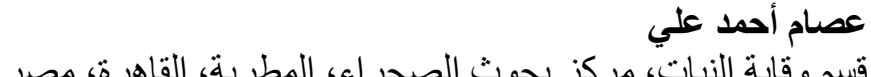

تعتبر ذبابة ثمار الزيتون الآفة الأكثر أهمية في آفات الزيتون. أجريت الدراسة بقرية

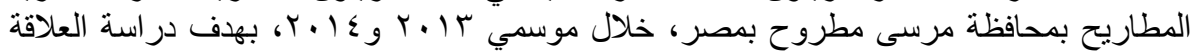

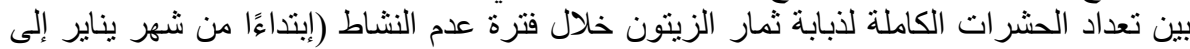

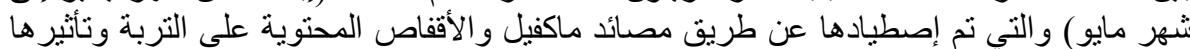

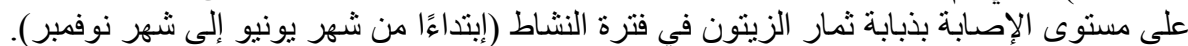

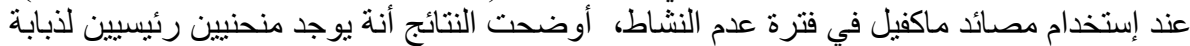

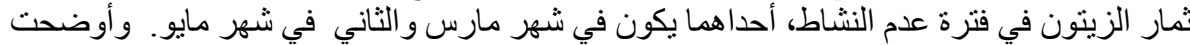

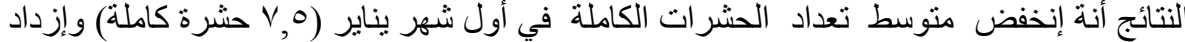

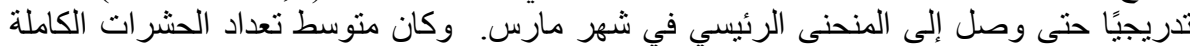

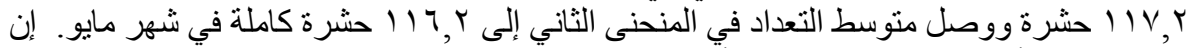

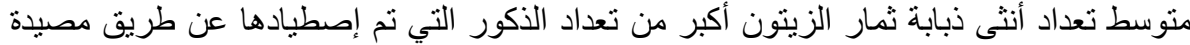

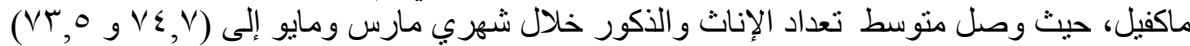

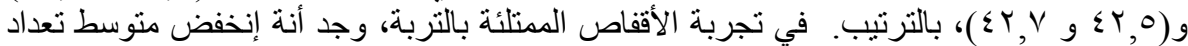

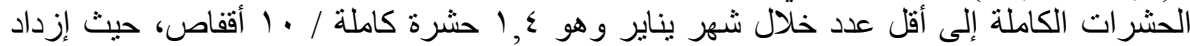

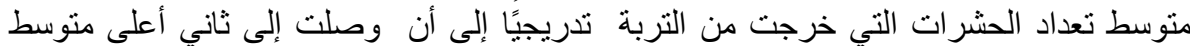

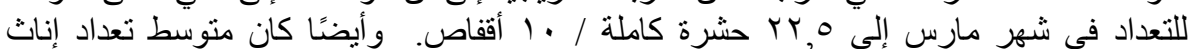

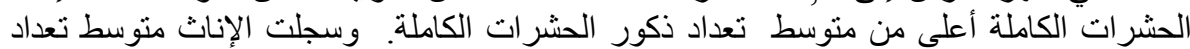

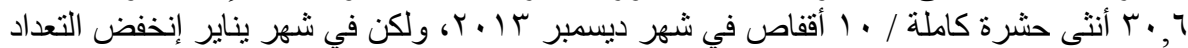

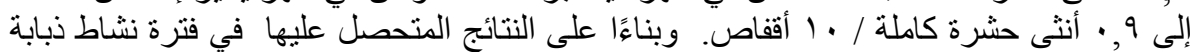

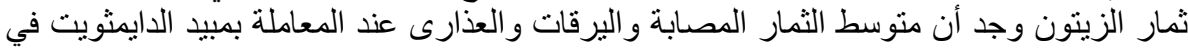

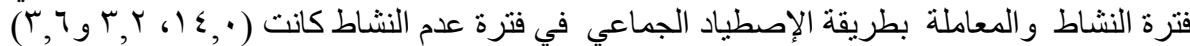

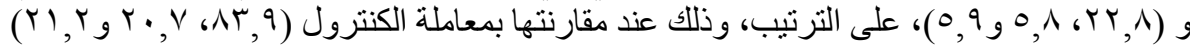

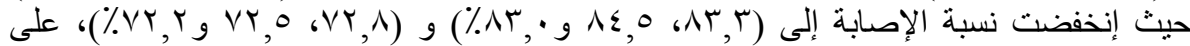

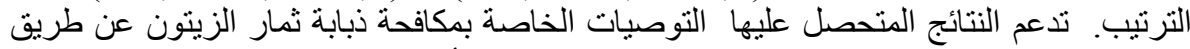

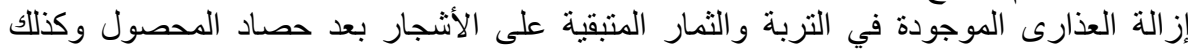

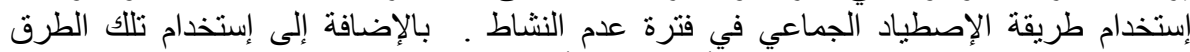

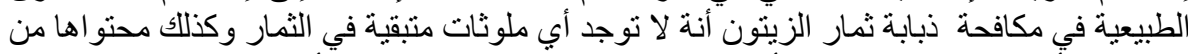

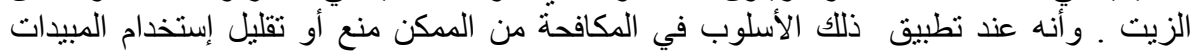

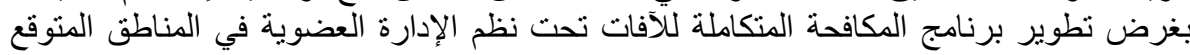

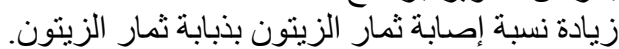

Egyptian J. Desert Res., 65, No. 1, 137-151 (2015) 